\section{Britain gives the green light}

\section{London}

THE British government's Department of Health today (16 January) releases a longawaited report expected to conclude that there are no serious ethical objections to somatic gene therapy. The report, from an independent committee chaired by the lawyer Sir Cecil Clothier, gives the green light to British research groups planning gene therapy experiments, and adds to the growing consensus in Europe that the ethical questions raised by the genetic manipulation of somatic cells are no more difficult than those surrounding organ transplantation.

Clothier's committee, set up two years ago, is thought have to made a clear distinction between somatic gene therapy and the manipulation of germ line cells. Like the otherEuropean ethical committees addressing the issue, led by the Dutch National Health Council which reported in late 1989, the British group is expected to recommend a moratorium on germ line therapy, which most geneticists say could lead to unpredictable effects in subsequent generations.

The Clothier report also comes just as innovation in gene therapy research, which began in the United States, expands to include Europe. Dinko Valerio is the Dutch researcher who first cloned the adenoside deaminase (ADA) gene used in the pioneering gene therapy experiments of French Anderson and Michael Blaese, from the National Institutes of Health in Bethesda, Maryland (see Nature 346, 402; 1990). Valerio hopes later this year to begin a clinical trial that may herald the treatment of genetic disorders by transplanting manipulated bone marrow cells. So far, the NIH experiments with ADA deficiency - an extremely rare inherited disorder - have involved the transformation of relatively short-lived lymphocytes, meaning that the successful treatment would require cells to be repeatedly transfused on a regular basis.

Valerio, who works at the Netherlands Organization for Applied Research's applied radiobiology and immunology institute at Delft, has completed successful trials of his technique in mice and rhesus monkeys. In both cases, the ADA gene was inserted into cultured bone-marrow cells by using a viral vector. After transplanting the marrow cells into his experimental animals, Valerio found that the ADA gene was expressed in a range of blood cell types. He is now waiting for approval of an ethics committee of the Dutch National Health Council, before going ahead with his human clinical trial.

In Britain, the Clothier report is unlikely to "open the floodgates" to a rush of gene therapy experiments, according to Sir David Weatherall, from the University of Oxford, who is a member of the Clothier committee; he says that few British research groups are ready to begin gene therapy. But Bob Williamson, whose cystic fibrosis research group at St Mary's Hospital in London is expected to be among the first to start, believes the report is important because it will inform and reassure the public. By distinguishing between somatic and germ line therapy, the report will point to "a middle course that will encourage scientists to go ahead sensibly," he says.

The expected activity of British geneticists in gene therapy research may introduce some new experimental approaches. In most experiments, genes have been inserted into somatic cells using viral vectors, but Williamson is exploring the use of artificial human chromosomes as vectors. The cystic fibrosis gene has been expressed in rats after transfer using an adenovirus vector, but there are some outstanding concerns about the safety of this delivery system arising from the possibility that viral vector DNA could recombine with wild type adenovirus sequences already present in the lungs.

Peter Aldhous

\section{Mute Magellan finds its voice}

\section{Washington}

MAGELLAN, the radar mapping probe now orbiting Venus, failed for seven days last week before mission engineers cobbled together a repair that will allow the spacecraft to continue at 40 per cent capacity. The failure, which rendered the Magellan's main transmitter inoperable, came at the end of the orbiter's successful first coverage of Venus, but before it could start a second set of passes that would yield a three-dimensional view of the planet's surface.

Engineers at the project's National Aeronautics and Space Administration (NASA) headquarters first detected the failure on 4 January, when they found that the orbiter was returning a clean signal, but no data. At first concerned that something had gone wrong with the radar instruments, the engineers were relieved to find that the data immediately reappeared at the usual 268,000 bits per second when they switched to the backup transmitter. But their reprieve was not to last. As the on-board electronics for the backup warmed up, that transmitter developed a noisy whistle that obscured the data. NASA project officials believe that there is a crack in a component that enlarges as the part heats up.
During the next week, NASA engineers tried several different transmission frequencies, trying to separate the data from the noise. But each time, either the whistle, or one of its harmonics, landed tried the transmitter at its lower transmission rate of 1,200 bits per second, normally used only for telemetry data. At Martin Marietta Corp./Science Photo Libran

\section{IMAGE UNAVAILABLE FOR COPYRIGHT REASONS}

Magellan in trouble. squarely on the data. Finally, the engineers this rate (which uses a far lower carrier and data frequency) the data finally came through cleanly. Although the lower transmission rate is only 40 per cent of normal, and the main antenna appears to be out for good, the probe can at least communicate again.

Magellan, initially scheduled to map only 70 per cent of Venus's surface, had, until the glitch last week, surpassed all expectations. It has mapped more than 95 per cent of the planet, and was filling in the last five per cent when the transmitter failed. This week, project engineers will send the probe new computer instructions to avoid further damage.

On 17 January, the orbiter will take a week off to recycle its batteries, and then on 23 January, it will begin the third part of its mission, filling in remaining gaps in the surface mapping, viewing previously mapped areas from a new angle to provide a 'stereo' three dimensional effect, and double checking some inexplicable altitude measurements, including one of a cliff that may be the highest in the solar system and a possible sign of active seismic activity on the planet. But unless the NASA engineers are able to fix the main transmitter, something that now seems unlikely, Magellan will be able to transmit only about half of what it sees, which will force project scientists to pick their targets carefully.
Christopher Anderson 